\title{
Infective endocarditis of an artificial aortic valve and native mitral valve after transcatheter aortic valve implantation
}

\author{
(D)Marko Perčić1*, \\ (DZZrinka Planinić', \\ (i)Ante Pašalić', \\ DTea Friščić', \\ DDaria Ljubas Perčić', \\ (D)Edvard Galićc, \\ (D)Jozica Šikić1,2 \\ 'University Hospital "Sveti \\ Duh", Zagreb, Croatia \\ ${ }^{2}$ University of Zagreb, School \\ of Medicine, Zagreb, Croatia
}

RECEIVED:

July 28, 2021

ACCEPTED:

August 5, 2021

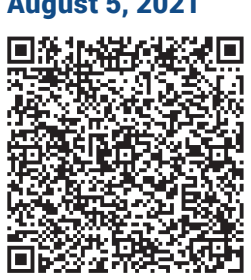

$\square$ Cardiologia Croatica 2021;16(9-10):292.
KEYWORDS: infective endocarditis, mitral regurgitation, transcatheter aortic valve implantation. CITATION: Cardiol Croat. 2021;16(9-10):292. | https://doi.org/10.15836/ccar2021.292

*ADDRESS FOR CORRESPONDENCE: Marko Perčić, Klinička bolnica „Sveti Duh“, Sv. Duh 64, HR-10000 Zagreb, Croatia. / Phone: +385-99-8451-823 E-mail: markopercicmef@gmail.com

ORCID: Marko Perčić, https://orcid.org/0000-0001-7904-8899 • Zrinka Planinić, https://orcid.org/0000-0001-8664-3338 Ante Pašalić, https://orcid.org/0000-0001-5989-6495 • Tea Friščić, https://orcid.org/0000-0003-3189-8661 Daria Ljubas Perčić, https://orcid.org/0000-0002-2672-2955 • Edvard Galić, https://orcid.org/0000-0002-5707-0961 Jozica Šikić, https://orcid.org/0000-0003-4488-0559

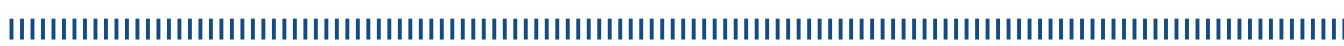

Introduction: Transcatheter aortic valve implantation (TAVI) is now a common procedure to treat highrisk patients with severe aortic stenosis ${ }^{1}$. The incidence of post-TAVI infective endocarditis is $3.25 \%$, but it is associated with high mortality and complications. The most common complication is heart failure with a cumulative incidence of $37.1 \%$. Appropriate measures should be taken to prevent infective endocarditis in post-TAVI patients including adequate antibiotics prophylaxis ${ }^{2}$.

Case report: We present a patient with history of implanted TAVI in December 2019, a condition after myocardial infarction and consequent secondary ischemic cardiomyopathy. In August 2020 he was hospitalized again at our Clinic because of acute heart failure and fever. Treatment was initiated according to guidelines for acute heart failure with non-invasive ventilation. Echocardiography was performed (EF 40\%), and a severe mitral regurgitation was verified (in two jets, one between A3 and P3 segment, and the other between A2 and P2 segment, PISA $1.2 \mathrm{~cm}$, EROA $0.7 \mathrm{~cm}^{2}$, MR RV $66 \mathrm{ml}$ ) with a visible vegetation on the anterior mitral cusp, on the atrial side, measuring $12 \times 6 \mathrm{~mm}$. Paravalvular "leak" of artificial aortic valve was visible, which reached the anterolateral papillary muscle with its jet, with PHT 423 ms. Also, minor abscess cavity beside artificial aortic valve was detected. S. Aureus was isolated from blood cultures, and linezolid was first introduced into the therapy, followed by vancomycin. Additionally, septic liver embolizations were radiologically verified. The patient's condition gradually deteriorated with volume retention and oliguria, and small doses of dobutamine $(5 \mathrm{mcg} / \mathrm{kg} /$ min) were administered. Significant clinical improvement was obtained with abundant diuresis and improvement in renal function. Patient was emergently transferred to the cardiac surgery by appointment for the planned surgical treatment of mitral valve endocarditis and TAVI removal with SAVR.

Conclusion: The mortality rate of infective endocarditis is $25 \%$. There is a higher incidence of infective endocarditis in those with prosthetic heart valves and cardiac devices. In these cases, urgent surgical intervention is necessary.

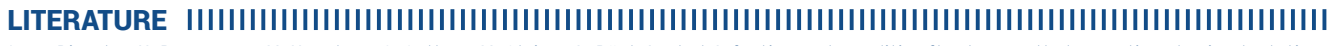

1. Bjursten H, Rasmussen M, Nozohoor S, Götberg M, Olaison L, Rück A, et al. Infective endocarditis after transcatheter aortic valve implantation: a nationwide study. Eur Heart J. 2019 0ct 14;40(39):3263-3269. https://doi.org/10.1093/eurheartj/ehz588

2. Khan A, Aslam A, Satti KN, Ashiq S. Infective endocarditis post-transcatheter aortic valve implantation (TAVI), microbiological profile and clinical outcomes: A systematic review. PLoS One. 2020 Jan 17;15(1):e0225077. https://doi.org/10.1371/journal.pone.0225077 